\title{
Verum accent IS VERUM, but not always focus
}

\author{
Cory Bill \& Todor Koev*
}

\begin{abstract}
This paper studies the occurrence of verum accent in declaratives and polar interrogatives. Verum accent exhibits two kinds of interpretational effect: (i) it requires an epistemic conflict across sentence types and (ii) it may also convey a negative speaker bias in polar interrogatives. We argue that the former effect is due to a presuppositional VERUM operator and that the latter effect arises from the possibility of said operator carrying polarity focus. Our proposal implies that verum accenting and polarity focus are two distinct phenomena that interact in interesting ways.
\end{abstract}

Keywords. verum accent; polarity focus; question bias

1. Introduction. The phenomenon of verum accent involves placing a pitch accent on the finite auxiliary and triggering certain interpretational effects (Höhle 1992). ${ }^{1}$ In this paper, we try to get a theoretical handle on this phenomenon by studying the occurrence of verum accent in declaratives and polar interrogatives. In declaratives, verum accent has the effect of emphasizing the truth of the prejacent, as shown in (1). In polar interrogatives, we get something close to the reverse effect to that in declaratives. In this latter case, a verum accent typically gives rise to a negative speaker bias toward the prejacent, see (2). ${ }^{2}$

Oliver IS from Australia.

$\rightsquigarrow$ It is true that Oliver is from Australia.

(2) Is Oliver from Australia?

$\rightsquigarrow$ The speaker doubts that Oliver is from Australia.

In both (1) and (2), we get the intuition that there is an epistemic conflict about the prejacent. That is, we get the intuition that the speaker's own belief about whether Oliver is from Australia does not match the evidence available in the context.

We propose that verum accent is the overt realization of an otherwise covert epistemic operator called VERUM (cf. Romero \& Han 2004; Gutzmann et al. 2020). According to our analysis, this operator has no truth-conditional import but it presupposes the existence of conflicting evidence about the prejacent. This is formalized in (3) below.

$\llbracket \operatorname{VERUM} \rrbracket_{c}(p)=p$,

provided that there is conflicting evidence about $p$ in $c$

The conflicting evidence presupposition associated with VERUM lies at the heart of the intuition that this operator is felicitous only in contexts in which there is a dispute about the prejacent. In addition, we argue that VERUM, qua polar operator, can carry contrastive focus mark-

\footnotetext{
* For stimulating feedback, we are indebted to the participants at the 95th Annual Meeting of the Linguistic Society of America as well as the audiences at ZAS and the University of Konstanz. The usual disclaimers apply. Authors: Cory Bill, Leibniz-Center General Linguistics (ZAS) (corybill@gmail.com) \& Todor Koev, University of Konstanz (tkoev@scarletmail.rutgers.edu). The research on this paper was funded by DFG grant KO 5704/1-1.

${ }^{1}$ Höhle's seminal observations are about German, where he claims that a verum accent can be realized on a finite auxiliary, a finite main verb, a complementizer, a relative pronoun, or similar CP-related elements. Here we limit our attention to accented finite auxiliaries as the most straightforward manifestation of this phenomenon in English.

${ }^{2}$ In linguistic examples, we use small caps as indicative of a pitch accent.
} 
ing (cf. Goodhue 2018). This is, we claim, the reason why polar questions with a verum accent may give rise to a speaker bias. We compare questions with a verum accent to questions with an accented negation, like Is Oliver NOT from Australia?, and show that the bias profiles of these two structures differ in several respects. We take this as evidence that a VERUM operator is not (always) focus marked and that it comes with its own semantics. Zooming out, this paper provides additional evidence for the general claim that verum accenting and polarity focus, while homophonous in English, are two related but distinct phenomena (see Höhle 1992; Romero \& Han 2004; Gutzmann et al. 2020).

The structure of the paper is as follows. Section 2 lays out the empirical landscape, describing the pattern of occurrence and the interpretational effects of verum accent in declaratives and polar interrogatives. Section 3 presents our proposal, which analyzes these effects in terms of two main planks: the meaning contribution of VERUM itself and the possibility that this operator carries polarity focus. In Section 4, we compare our proposal to prior accounts and argue that none of them quite provides the empirical coverage that we offer. Section 5 is the conclusion and also includes a brief discussion of other apparent uses of verum accent.

2. The empirical landscape. This section looks into the occurrence of verum accent in declaratives and polar interrogatives. We argue that verum accent has two main interpretational effects: epistemic contradiction and speaker bias. The first effect is obligatorily present in both kinds of clauses. The second effect is optional and is only attested in polar interrogatives.

2.1. VERUM ACCENT IN DEClARATIVES. Gutzmann et al. (2020) observe that a verum accent in declaratives is felicitous in two kinds of contexts: contradiction and affirmation. Contradiction contexts constitute the canonical case and arise when there is some dispute about whether the prejacent is true or false. A typical example is cited in (4).

(4) a. A: Oliver is not from Australia.

(contradiction context)

b. B: No, he Is from Australia.

Affirmation contexts exhibit the reverse situation. Such contexts come about when the speaker and the addressee both agree on the prejacent. (5) provides an example.

(5) After a colloquium talk...

(affirmation context)

a. A: Paula is an amazing linguist.

b. B: She IS an amazing linguist.

We stress that an affirmation context typically involves extreme adjectives like amazing, awesome, excellent, etc. (Cruse 1986; Paradis 2001; Morzycki 2012; also Umbach 2011 on extreme verbs). This will become important in Section 3.1, where we will argue that - despite appearances - affirmation contexts are just contradiction contexts in another guise. Notice that a verum accent is also licensed in affirmation contexts that contain regular predicates, although the result is once again an "extreme" interpretation. For example, if It IS raining has been uttered as a reaction to It's raining, it will usually suggest a heavy rain and not just a light drizzle. Similarly, He IS a Russian, when uttered after He is a Russian, creates the impression that the person in question acts in ways stereotypical for Russian males, whatever these might be.

Gutzmann et al. (2020) also notice that a verum accent is out in neutral contexts, or contexts that are not conflicted about the prejacent. An example is shown in (6) below.

Out of the blue...

(neutral context) 
a. A: Is it snowing outside?

b. B: \#It IS snowing.

We note that an out-of-the-blue context need not be neutral (in the intended sense). Thus, a verum-marked declarative may be quite felicitous as a conversation starter if an epistemic conflict can easily be accommodated, for example because such a conflict goes back to another conversation that both speaker and addressee have just witnessed. Still, out-of-the-blue utterances are typically a good way to suggest that there has been no prior dispute or discussion about the prejacent.

2.2. VERUM ACCENT IN POLAR INTERROGATIVES. Just like in declaratives, when a verum accent features in polar interrogatives, we get the intuition of an epistemic conflict. For example, in order for a question like Is it raining outside? to be felicitous, the speaker must think that it is not raining outside but her belief must be contradicted by contextual evidence. In addition to signaling an epistemic conflict, verum accent in polar interrogatives may also convey a speaker bias (Romero \& Han 2004). Example (7) is repeated from (2) above.

(7) Is Oliver from Australia?

$\rightsquigarrow$ The speaker doubts that Oliver is from Australia.

Importantly, the bias associated with verum accent in polar interrogatives is optional, as it can disappear in certain contexts. One such context is (8), where evidence for and against the prejacent has been provided by other parties and the speaker herself does not take a stand. The examples in (9) and (10) are drawn from the literature and make the same point.

(8) DID Mary join the team? Because some say she did, others say she didn't. $\leftrightarrow \rightarrow$ The speaker doubts that Mary joined the team.

(9) a. A: Did Karl kick the dog?

(Gutzmann et al. 2020: 41)

b. B: No, Karl didn't kick the dog.

c. C: No, he DID kick the dog.

d. A: Which is it? DID he kick the dog?

$\leftrightarrow \rightarrow$ The speaker doubts that Karl kicked the dog.

(10) B wants to know whether Jill will be at a meeting for members of a club. But B lacks an opinion about whether Jill is a member.

(Goodhue 2019: 473)

a. B: Will Jill be at the meeting?

b. A: If she's a member, she will.

c. B: Is she a member?

$\leftrightarrow \rightarrow$ The speaker doubts that Jill is a member.

Other tests for bias optionality give rise to the same result. Sadock (1971) and Reese \& Asher (2010) note that the marker by any chance only occurs in neutral questions, as it is incompatible with any degree of speaker bias. For example, this marker is fine in positive polar questions, which may but need not be biased, but it is out in polar questions with epistemic really, which obligatorily convey a bias. The relevant contrast is illustrated in (11)-(12).

(11) Does John drink alcohol, by any chance? (optional bias)

(12) \#Does John REALLY drink alcohol, by any chance? (obligatory bias) 
Since verum-marked questions are fine with the neutrality marker by any chance, as shown in (13), we have additional evidence that a verum accent in polar questions need not trigger a speaker bias.

(13) DID Mary join the team, by any chance?

3. Proposal. In the previous section, we looked into the interpretational effects of verum accent in declaratives and polar interrogatives. We found that verum accent gives rise to an epistemic contradiction across sentence types and that it may trigger a negative speaker bias in polar interrogatives. Given our findings, we need to answer the following three questions: (i) Why is there a consistent effect of an epistemic contradiction across verum-marked sentence types? (ii) What triggers the negative speaker bias in verum-marked polar interrogatives? (iii) Why is such bias optional? This section offers answers to these questions in terms of two main ingredients: a VERUM operator and polarity focus. We also draw a comparison between verum accent and accented negation, thus establishing that the question bias profiles associated with these two elements significantly differ. As we will argue in Section 4, this is an important result that gives an edge to our proposal over competing accounts.

3.1. A SEMANTICS FOR VERUM. As already mentioned in the Introduction, we take verum accent to be the overt realization of a purely presuppositional VERUM operator. The meaning for VERUM was stated in (3) and is repeated in (14).

$\llbracket \operatorname{VERUM} \rrbracket_{c}(p)=p$

provided that there is conflicting evidence about $p$ in $c$

We assume that conflicting evidence about $p$ involves two mutually exclusive pieces of evidence; a piece of evidence for $p$ and a piece of evidence against $p$. Notice that contrasting evidence alone does not suffice, as such evidence need not produce an epistemic conflict and VERUM may not be licensed. Thus, if the positive and the negative pieces of evidence are presented as mere possibilities, a verum-marked sentence is not fully natural, as shown in (15). ${ }^{3}$

a. A: It's possible that Oliver is from Australia.

b. B: It's also possible that he is from New Zealand (though).

c. C: ?No, he IS from Australia.

We now demonstrate that this simple semantics already predicts the distribution of VERUM in declarative sentences across contexts. Starting with contradiction contexts, recall from example (4), repeated below as (16), that the prototypical use of verum accent is in denials to negative utterances.

(16) a. A: Oliver is not from Australia.

b. B: No, he Is from Australia.

In this case, the epistemic conflict required by VERUM is generated as follows: the negative evidence comes from the previous utterance while the positive evidence may have two different sources. One option is that this latter evidence may be due to yet a prior positive utterance that the negative utterance takes issue with. After all, one would not utter a negative sentence if the positive alternative had not been raised. In (16), for example, A's utterance will typically

\footnotetext{
${ }^{3}$ Notice that C's utterance in (15) is not entirely out. The reason, we suggest, is that strong positive evidence can be
} accommodated from C's verum-marked assertion, thus deriving the required conflict with B's utterance. 
be understood as a reaction to a prior suggestion or assertion of Oliver is from Australia. Even in the absence of such prior utterance, an epistemic conflict can be accommodated from the fact that the verum-marked sentence is being asserted by B and thus it is strongly supported by the evidence. Either way, we get the intuition of emphasis on the truth of the prejacent, as required.

Moving on to affirmation contexts, we remarked in Section 2.1 that such uses typically involve extreme adjectives (or, more generally, extreme readings of predicates). Example (17) is repeated from (5) above.

\section{After a colloquium talk...}

a. A: Paula is an amazing linguist.

b. B: She IS an amazing linguist.

Morzycki (2012) offers the most elaborate account of extreme adjectives to date, claiming that such adjectives make use of the far end of the scale associated with the respective regular adjective. The basic idea is that lexical scales are contextually restricted to a given range, and extreme adjectives involve degrees that have "gone off" the maximum of this range. Following up on this idea, we can say that in (17) the extreme adjective amazing is parasitic on the regular adjective good, as it refers to extreme degrees of goodness. This derives the required epistemic conflict as follows. Let us assume that $\langle$ good, amazing $\rangle$ forms a Horn-scale, such that a sentence with amazing naturally invokes the respective alternative with good. In (17), A's initial utterance of Paula is an amazing linguist will invoke the weaker (or entailed) alternative Paula is a good linguist. Now, if we allow that this latter alternative be strengthened to Paula is a good but not an amazing linguist by some standard scalar mechanism, we get an alternative that contradicts B's verum-marked sentence She IS an amazing linguist. In other words, the use of an extreme adjective creates an implicit contraction within the same scale by splitting it into two non-overlapping regions. Once we broaden our view beyond polar contradictions, we see that affirmation contexts are just a special case of contradiction contexts. ${ }^{4}$

Finally, our semantics for VERUM straightforwardly derives the observation that verum accent is out in neutral contexts. Since such contexts lack conflicting evidence about the prejacent, the presupposition of VERUM is not satisfied and a verum-marked sentence is out.

Our proposal has gone a long way in deriving the distribution of verum-marked declaratives across contexts. But one thing our semantics does not buy us is the occasional intuition of speaker bias attached to verum-marked polar interrogatives. The conflicting evidence presupposition requires a dispute about the prejacent, so it is natural to assume that - at least in some cases - the speaker has a preference for one of the two question alternatives. However, since this presupposition is "symmetric" in merely signaling a conflict and without involving the speaker, we cannot derive the negative polarity of the speaker bias (in the cases in which such bias is present). There is a missing ingredient that decides on the direction of the bias, and in the next section we argue that this ingredient is polarity focus.

\footnotetext{
${ }^{4}$ Although we do not propose an explicit analysis of affirmation uses that lack extreme predicates, we think that Morzycki's (2012) distinction between lexical and contextual extreme predicates provides a clue of how such cases are to be handled. More specifically, we suggest that such cases involve contextually extreme predicates (or respective readings). That is, a context may support a reading of an ordinary predicate whereby its standard falls outside the salient portion of the scale.
} 
3.2. PolARITY FOCUS. Focus is prosodic prominence that facilitates interpretation in some way. Here we adopt Rooth's alternative semantics, which models focus as a feature $F$ that marks syntactic constituents and elicits alternatives relevant for interpretation (Rooth 1985; 1992; 1997; for related ideas, see Jackendoff 1972; Hamblin 1973; Kratzer 1991; Selkirk 1995; Schwarzschild 1999; Beck 1999; Beaver \& Clark 2008; Büring 2016; a.o.). According to Rooth's theory, each linguistic expression is associated with two semantic values: ordinary and focus. The ordinary semantic value of a simple expression $\alpha$ is rendered as $\llbracket \alpha \rrbracket^{o}$ and corresponds to its usual denotation. The focus semantic value of $\alpha$ is rendered as $\llbracket \alpha \rrbracket^{f}$ and is always a set, although its shape varies based on whether the expression is focus-marked or not. When $\alpha$ is not focused, its focus value is the singleton set comprised of the ordinary value of $\alpha$. In contrast, when $\alpha$ is focused, its focus value is the set comprised of all alternative objects that are of the same semantic type as the ordinary value of $\alpha$. This is formalized in (18).

\section{LEXICAL ITEMS}

a. $\quad \llbracket \alpha \rrbracket^{f}=\left\{\llbracket \alpha \rrbracket^{o}\right\}$

b. $\llbracket \alpha_{F} \rrbracket^{f}=\left\{x \in D_{\tau} \mid \llbracket \alpha \rrbracket^{o} \in D_{\tau}\right\}$

(non-focused items)

(focused items)

The focus semantic value of complex expressions is derived from the focus values of their immediate constituents by composing alternatives in a pointwise fashion and letting them project up the tree. This is ensured by the procedure outlined in (19).

Pointwise FunCtion APPLiCATION

If $\llbracket \alpha \rrbracket^{o} \in D_{\sigma \rightarrow \tau}$ and $\llbracket \beta \rrbracket^{o} \in D_{\sigma}$, then $\llbracket[\alpha \beta] \rrbracket^{f}=\llbracket[\beta \alpha] \rrbracket^{f}=\left\{x(y) \in D_{\tau} \mid x \in \llbracket \alpha \rrbracket^{f}\right.$ and $y \in$ $\left.\llbracket \beta \rrbracket^{f}\right\}$.

Consider (20) as an example. (18-a), in conjunction with (19), tells us that the focus semantic value of the predicate drinks beer is the singleton set comprised of its ordinary value. In turn, (18-b) tells us that the focus semantic value of Mary $F$ is the set comprised of all individuals in the domain, e.g. Mary, Jane, and Susan. Composing the two focus values via (19), we obtain the entire range of propositional alternatives corresponding to Mary drinking beer, Jane drinking beer, and Susan drinking beer. The formal derivation is given in (20). ${ }^{5}$

MARY drinks beer.

a. [те Mary $F$ [vP drinks beer] $]$

b. $\llbracket$ beer $\rrbracket^{f}=\{$ beer $\}$

$\llbracket \operatorname{drinks} \rrbracket^{f}=\left\{\lambda y \lambda x \lambda w . \operatorname{drink}_{w}(x, y)\right\}$

$\llbracket[$ vp drinks beer $] \rrbracket^{f}=\left\{\lambda x \lambda w . \operatorname{drink}_{w}(x\right.$, beer $\left.)\right\}$

$\llbracket \operatorname{Mary}_{F} \rrbracket^{f}=\{$ mary, jane, susan $\}$

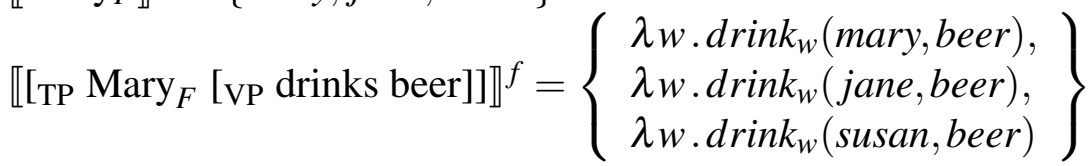

Focus marking can be interpreted as semantic or pragmatic. Semantic focus has a truthconditional effect and involves a conventional association between an operator (like only or even) and a focus-marked constituent in its scope. More important for our purposes is pragmatic focus, which has no truth-conditional effect but facilitates discourse coherence. It does

\footnotetext{
${ }^{5}$ Why is beer, as well as any other non-human objects that may feature in the domain, excluded from the focus value
} of Mary? We assume that this is because otherwise we would get implausible focus alternatives. 
so by requiring that a certain antecedent be present in the discourse (or else it needs to be accommodated). The nature of this antecedent depend on the function pragmatic focus plays in a given utterance. The two main functions that pragmatic focus has been linked to are presentational and contrastive. Presentational focus marks the new information introduced by the utterance by invoking a structurally similar or "congruent" question as an antecedent. More formally, the question antecedent of presentational focus stands in a given relation to the focus domain (the focus-bearing clause) by imposing three conditions: (i) the question is a subset of the focus semantic value of the domain (a congruence requirement), (ii) the question contains the ordinary value of the domain (an answerhood requirement), and (iii) the question contains at least one additional alternative (a choice requirement). In turn, contrastive focus marks a phrase whose referent is juxtaposed with the referent of a similar antecedent phrase. Formally, contrastive focus imposes two conditions on the antecedent referent: (i) it is a member of the focus value of the domain (a similarity requirement) and (ii) it differs from the ordinary meaning of that domain (a contrast requirement). Rooth (1992: 90) defines these two varieties of pragmatic focus as in (21), where the squiggle operator $\sim$ joins the focus domain $\phi$ to an antecedent $C$ by issuing in one of the two presuppositions listed below.

(21) $\phi \sim C$ is felicitous only if one of the following holds:

a. $C \subseteq \llbracket \phi \rrbracket^{f}, \llbracket \phi \rrbracket^{o} \in C$, and $\exists p \in C: p \neq \llbracket \phi \rrbracket^{o}$

b. $\quad C \in \llbracket \phi \rrbracket^{f}$ and $C \neq \llbracket \phi \rrbracket^{o}$

(presentational focus)

(contrastive focus)

As an illustration, consider again the sentence in (20). The focus marking will be interpreted as presentational in the context presented in (22) (we assume that Mary and Jane are the only salient individuals in the context). That is, the focus domain meets all three conditions for presentational focus stated in (21-a).

A: Who drinks beer? B: MARY drinks beer.

a. $\quad\left[\text { Tе } \operatorname{Mary}_{F}[\text { vP drinks beer }]\right]_{\phi} \sim C$

b. $\quad C=\llbracket$ Who drinks beer? $\rrbracket^{o}=\left\{\begin{array}{l}\lambda w \cdot \text { drink }_{w}(\text { mary }, \text { beer }), \\ \lambda w \cdot \text { drink }_{w}(\text { jane }, \text { beer })\end{array}\right\}$

$$
\begin{aligned}
& \llbracket \phi \rrbracket^{o}=\lambda w . \text { drink }_{w}(\text { mary }, \text { beer }) \\
& \llbracket \phi \rrbracket^{f}=\left\{\begin{array}{l}
\lambda w . \text { drink }_{w}(\text { mary }, \text { beer }), \\
\lambda w . \text { drink }_{w}(\text { jane }, \text { beer }), \\
\lambda w . \text { drink }_{w}(\text { susan }, \text { beer })
\end{array}\right\}
\end{aligned}
$$

c. $\quad C \subseteq \llbracket \phi \rrbracket^{f} \checkmark, \llbracket \phi \rrbracket^{o} \in C \checkmark, \quad \exists p \in C: p \neq \llbracket \phi \rrbracket^{o} \checkmark$

In contrast, the focus marking of the very same sentence is interpreted as contrastive in the context in (23), as both conditions in (21-b) are satisfied.

(23) Jane drinks beer and MARY drinks beer (too).

a. $[\text { Tе Mary } F[\text { vP drinks beer }]]_{\phi} \sim C$

b. $\quad C=\llbracket$ Jane drinks beer $\rrbracket^{o}=\lambda w \cdot \operatorname{drink}_{w}($ jane, beer $)$

$\llbracket \phi \rrbracket^{o}=\lambda w . \operatorname{drink}_{w}($ mary, beer $)$

$\llbracket \phi \rrbracket^{f}=\left\{\begin{array}{l}\lambda w . \text { drink }_{w}(\text { mary }, \text { beer }), \\ \lambda w . \text { drink }_{w}(\text { jane }, \text { beer }), \\ \lambda w . \text { drink }_{w}(\text { susan }, \text { beer })\end{array}\right\}$

c. $\quad C \in \llbracket \phi \rrbracket^{f} \checkmark, \quad C \neq \llbracket \phi \rrbracket^{o} \checkmark$ 
Just like focus can mark any other phrase, it can also mark a polar operator. This variety of focus is often called polarity focus (Höhle 1992; Wilder 2013; Büring 2016; Samko 2016; Goodhue 2018). ${ }^{6}$ A polar operator is one that determines the polarity of the host clause, i.e. it entails the prejacent or its negation. Two such operators in English are VERUM and not. ${ }^{7}$ The ordinary semantics for VERUM was already stated in (14) and the ordinary semantics for negation is just set-theoretic complementation. As for their focus semantic values, we assume that these are equivalent and consist of the two most basic functions on propositions, i.e. identity and complementation, as shown in (24).

$$
\llbracket \operatorname{VERUM}_{F} \rrbracket^{f}=\llbracket \operatorname{not}_{F} \rrbracket^{f}=\{\lambda p \cdot p, \lambda p \cdot \bar{p}\}
$$

Essentially, this is the set comprised of the ordinary meanings for VERUM and negation, where the presupposition associated with the former operator is ignored. ${ }^{8}$

We make two important assumptions about polarity focus. ${ }^{9}$ The first assumption is that the domain of polarity focus is the minimal clause that contains the focused polar operator. That is, we assume that the squiggle operator applies as soon as a focused polar operator is merged with its prejacent. We will not speculate why this should be so, although it stands to reason that this is a reflex of some economy constraint. The second assumption is that polarity focus always receives a contrastive interpretation. This is likely due to the fact that polarity focus invokes two well-defined and complementary alternatives, so picking out one of them necessarily contrasts with the other alternative. This latter assumption also follows a more general line of thought, which views contrastive focus as focus proper and which relegates new/given information marking to a separate mechanism (see Kratzer \& Selkirk 2020 and the references therein).

3.3. POlaRity FOCUS AND QUESTION BIAS. We now come to discuss the role of polarity focus in deriving bias in polar interrogatives with VERUM. Recall from Section 2.2 that such structures convey a negative speaker bias, which however need not always arise.

DID Mary join the team?

Optional inference: The speaker doubts that Mary joined the team.

In order to derive the optionality of speaker bias, we propose that verum-marked polar interrogatives may be associated with two homophonous Logical Forms, one with and another without focus marking. While both forms contain VERUM and thus require conflicting evidence about the prejacent, only the variant in which VERUM carries polarity focus conveys a bias. That is, we propose that (25) is ambiguous between (26-a) and (26-b).

a. [CP Q [TP VERUM [TP Mary join the team]]]

(unbiased)

b. $\quad\left[\mathrm{CP} \mathrm{Q}\left[\mathrm{TP} \operatorname{VERUM}_{F}[\mathrm{TP} \text { Mary join the team }]\right]_{\phi} \sim C\right]$

(biased)

\footnotetext{
${ }^{6}$ Another common label is "verum focus". However, since we argue that verum accenting and polarity focus are two distinct phenomena, we find this terminology confusing and will not be using it.

${ }^{7}$ More formally, a polar operator $O$ is veridical $(O p \vDash p)$ or antiveridical $(O p \vDash \bar{p})$. This begs the question of what other polar operators there are in English beyond VERUM and not. Epistemic uses of really, definitely, totally, and so seem like plausible examples (see Laka 1990; Barker 2002; Partee 2004; Romero \& Han 2004; Beltrama 2018).

${ }^{8}$ In other words, ignoring not-at-issue content, we can write $\llbracket \operatorname{VERUM}_{F} \rrbracket^{f}=\llbracket \operatorname{not}_{F} \rrbracket^{f}=\left\{\llbracket \mathrm{VERUM} \rrbracket^{o}, \llbracket\right.$ not $\left.\rrbracket^{o}\right\}$.

${ }^{9}$ Both of these assumptions about polarity focus are already present in Wilder (2013), Samko (2016), and Goodhue (2018), albeit in an implicit form.
} 
The ordinary meaning of (26-a) is the usual question partition that is comprised of the prejacent proposition and its complement. Since this structure also contains VERUM, it generates the presupposition of conflicting evidence about the prejacent. This is illustrated in (27).

$$
\begin{aligned}
& \text { a. [CP Q [TP VERUM [TP Mary join the team }]]] \\
& \text { b. } \llbracket \mathrm{CP} \rrbracket_{c}^{o}=\left\{\begin{array}{l}
\lambda w \cdot \text { join }_{w}(\text { mary }, \text { team }), \\
\lambda w . \neg \text { join }_{w}(\text { mary }, \text { team })
\end{array}\right\},
\end{aligned}
$$

provided that there is conflicting evidence about $\lambda w$. join $_{w}($ mary,team) in $c$

Notably, no part of the evidence needs to originate from the speaker and it can stem from other contextual sources entirely. This accounts for the optionality of the bias associated with verum-marked questions.

In turn, (26-b) gives rise to the same question denotation and conflicting evidence presupposition. However, in this case VERUM is focus marked and thus requires an antecedent. Given that polarity focus is contrastive, the only antecedent that meets the condition in (21-b) is the negative question alternative, as shown in (28).

a. $\quad\left[\mathrm{CP} \mathrm{Q}\left[\mathrm{TP} \operatorname{VERUM}_{F}[\mathrm{TP} \text { Mary join the team }]\right]_{\phi} \sim C\right]$

b. $\quad C=\lambda w . \neg \operatorname{join}_{w}(\text { mary }, \text { team })^{2}$

$\llbracket \phi \rrbracket_{c}^{o}=\lambda w$. join $_{w}($ mary, team $)$,

provided that there is conflicting evidence about $\lambda w$. join $_{w}($ mary,team) in $c$

$\llbracket \phi \rrbracket_{c}^{f}=\llbracket \mathrm{CP} \rrbracket_{c}^{o}=\left\{\begin{array}{l}\lambda w \cdot \text { join }_{w}(\text { mary, team }), \\ \lambda w \cdot \neg \text { join }_{w}(\text { mary }, \text { team })\end{array}\right\}$,

provided that there is conflicting evidence about $\lambda w$. join $_{w}($ mary,team) in $c$

c. $\quad C \in \llbracket \phi \rrbracket^{f} \checkmark, \quad C \neq \llbracket \phi \rrbracket^{o} \checkmark$

The presence of polarity focus in verum-marked polar interrogatives derives the negative speaker bias as follows. First, since the focus antecedent is resolved to the negative question alternative, the production of such forms suggests that this alternative is salient in the context. In addition, uttering a polar interrogative constitutes a request for evidence for the prejacent proposition. The utterer of a verum-marked polar interrogative is then questioning the focus domain proposition while at the same time pointing to the negative alternative. So she must have a preference for said alternative, hence the negative bias.

We have derived both the optionality and the negative direction of the speaker bias in polar interrogatives with VERUM. The optionality follows from the assumption that VERUM, qua polar operator, may (though need not) carry focus marking. The negative direction is due to the fact that when such marking is present, the contrasting antecedent will be resolved to the negative question alternative.

One might wonder what our account predicts about focused VERUM in declaratives. Here we generate no speaker bias. The reason is that while the focus marking will be interpreted as contrasting with a negative antecedent, in this case the speaker is not asking for evidence for the prejacent proposition but rather asserting said proposition and thus providing evidence for it. This suggests that, unlike in polar interrogatives, the speaker has a preference for the positive (or asserted) proposition. However, this preference is not expected to be visible as it is "swamped" by the norm for assertion, which independently requires strong evidence. ${ }^{10}$

${ }^{10}$ Still, in some cases the effect of focus on VERUM in declaratives might be visible in the form of a structurally 
3.4. VERUM ACCENT VS. ACCENTED NEGATION. Sentences with verum accent and sentences with accented negation have often been lumped together, with the understanding that they only differ in polarity. (29) provides a (putative) minimal pair.

a. Vegetarians DO eat fish.

b. Vegetarians do NOT eat fish.

Despite this superficial similarity, we argue that these two kinds of accenting are more different than meets the eye. Specifically, we propose that accented negation is just polarity focus on regular negation. Since polarity focus requires a positive antecedent that contrasts with the negative prejacent, accented negation produces an effect similar to that with VERUM. However, the interpretational effects of these two kinds of accenting peel apart when one looks at speaker bias. We now demonstrate that our proposal makes the correct predictions about speaker bias in polar interrogatives with accented negation.

Polar interrogatives with accented negation are assumed to have Logical Forms as in (30). ${ }^{11}$

a. Do vegetarians NOT eat fish?

b. $\quad\left[\mathrm{CP} \mathrm{Q}\left[\mathrm{TP} \operatorname{not}_{F}[\mathrm{TP} \text { vegetarians eat fish }]\right]_{\phi} \sim C\right]$

First, notice that we predict a positive speaker bias by the same mechanism that applies in polar interrogatives with focused VERUM. That is, since the speaker in (30) puts into question the negative focus domain while pointing at the contrasting positive alternative, she conveys a preference for that alternative. Hence the implication that the speaker believes that vegetarians eat fish.

In addition, recall from Section 2.2 that verum-marked polar interrogatives are only optionally biased (as they may but need not contain focus). This is not the case for polar interrogatives with accented negation, which are obligatorily biased, as indicated by their inability to be felicitously combined with the neutrality modifier by any chance in (31). ${ }^{12}$

\#Do vegetarians NOT eat fish, by any chance?

The obligatoriness of bias follows from the simple fact that accented negation involves polarity focus and that such focus is necessarily interpreted as contrastive.

Finally, notice that speaker bias comes in different strengths. In polar interrogatives with VERUM, the bias (when present) is strong and can be self-described by strong modals like be certain. In polar interrogatives with accented negation, the bias is weak and has to be selfdescribed by weak modals like suspect. This is illustrated in (32). ${ }^{13}$

similar antecedent. This line of explanation is given in Samko (2016: 113) for the infelicity in (i).

(i) a. A: Ok, now that Stephan has come, we are all here. Let's go!

b. S: \#Jane IS coming (too).

We leave the role of focus on VERUM declaratives to future work.

${ }^{11}$ Here we only discuss polar interrogatives with (accented) low negation. We leave the analysis of bias in polar interrogatives with high negation (as in Don't vegetarians eat fish) to another occasion.

${ }^{12}$ What causes the clash here is indeed the accent on negation co-occurring with by any chance. Unaccented negative polar interrogatives need not be biased and are fine in this context (cf. Do vegetarians not eat fish, by any chance?).

${ }^{13}$ One might wonder why in (32-a) the weaker follow-up with suspect is disallowed even though the strong speaker bias clearly meets the threshold for suspect. We suggests that this is for pragmatic reasons, i.e. the acceptibility of the stronger be certain-based follow-up blocks the possibility of the weaker suspect-based follow-up. 

a. Do vegetarians eat fish? That is to say, $\left\{\begin{array}{l}\# I \text { suspected } \\ \text { I was certain }\end{array}\right\}$ they didn't.
b. Do vegetarians NOT eat fish? That is to say, $\left\{\begin{array}{c}\text { I suspected } \\ \text { \#I was certain }\end{array}\right\}$ they did.

We can derive this contrast as follows. The focus marking on negation only conveys a preference for the positive question alternative and the generated bias is expected to be weak. The same is true about the focus on VERUM, which generates a preference for the negative question alternative. However, VERUM also introduces the presuposition that the context is conflicted about the prejacent, so the bias gets a boost. In other words, if biased at all, polar interrogatives with VERUM are strongly biased.

4. Prior accounts of verum accent. There are two main approaches to theorizing about verum accent. The focus approach posits that verum accent involves narrow focus on a polarity head and manifests itself as a pitch accent somewhere in the left periphery of the sentence. In contrast, the operator approach - of which our own proposal is an instantiation - posits that verum accent is the spelling out of an epistemic/common ground operator with a semantic import of its own. In this section, we critically evaluate three prior accounts to verum accent and argue that none of them quite matches our proposal in empirical predictions.

4.1. Goodhue (2018). One instantiation of the focus approach is Goodhue (2018), which builds on Laka (1990), Wilder (2013), and Samko (2016). Goodhue's basic idea is that verum accent is just polarity focus, i.e. (on his view) focus on a syntactically represented polarity head. The interpretational effects of verum accent are then to be explained within a general theory of focus (such as Rooth's alternative semantics) and pragmatic reasoning. ${ }^{14}$

The main advantage of Goodhue's account of verum accent lies in its theoretical parsimony. The account does not posit a special-purpose VERUM operator and aims at capturing the data by what is already provided by the theory of focus. However, we suggest that focus alone is not enough to derive all facets of the data.

Starting with the distribution of verum accent, Goodhue's polarity focus account can easily derive its occurrence in contraction and affirmation contexts (recall (4) and (5)). Since both contexts create an (overt or covert) contradiction, polarity focus can be interpreted as contrasting with the polar alternative provided by the context. However, this account struggles to explain why verum accent is infelicitous in a neutral context (recall (6)), as it is unclear what would prevent a presentational focus interpretation in this case. ${ }^{15}$ In order to block a presentational interpretation, we need to make two additional assumptions (cf. Goodhue 2018: 7-8): (i) polarity focus is always contrastive (as we ourselves have assumed) and (ii) only "pronounced" question alternatives are salient enough to serve as focus antecedents. In light of these two assumptions, a sequence of a neutral question and a verum-marked answer will be out (e.g. $A$ : Is it raining? B: \#It IS raining.), as the focus marking on the finite auxiliary will lack a contrasting/negative antecedent.

\footnotetext{
${ }^{14}$ Goodhue (2018), as well as all other accounts in the same lineage, seem to predict that verum accent and accented negation are in complementary distribution. The reason is that, if present, the polarity head in a given clause is specified as either "positive" or "negative". It is difficult to square this prediction with the simple observation that verum accent and accented negation readily co-occur (cf. DOES Bill NOT drink alcohol?).

${ }^{15}$ In fact, given the principle of maximize presupposition (Heim 1991), we expect verum accent to be obligatory after neutral questions.
} 
As for speaker bias in verum-marked polar interrogatives, it is claimed to follow from two general principles, i.e. ignorance and opinionatedness (or "homogeneity") about the prejacent proposition. Ignorance states that, in asking a question ? $p$ after a suggestion or assertion of $p$, the speaker signals that she lacks the belief that $p$, while opinionatedness adds that the speaker believes $p$ or that she believes $\bar{p}$. Putting these two things together, we get the stronger inference that the speaker believes $\bar{p}$. Although this reasoning correctly derives the negative direction of bias in verum-marked polar questions, notice that the derivation makes no use of polarity focus and thus is burdened with predictions about non-verum questions (see original paper for discussion). In turn, the presence of speaker bias will depend on whether one makes the opinionatedness assumption, which now has to be decided on a purely contextual basis and is not tied to a particular linguistic signal like polarity focus. The main challenge for this account, as we see it, is to explain why the bias in verum-marked polar interrogatives is strong and thus different from the weak bias conveyed by polar interrogatives with accented negation. On this account, we expect both of these structures to involve polarity focus and only differ in bias polarity, contrary to what we found in Section 3.4.

4.2. ROMERO \& HAN (2004). One prominent account within the operator approach is Romero \& Han (2004) (for elaborations, see Repp 2013; Goodhue 2019; Silk 2020). According to it, verum accent realizes a conversational operator VERUM that signals common ground negotiation. ${ }^{16}$ More specifically, VERUM states that the speaker is certain that the prejacent proposition should be added to the common ground. This is formalized in (33), where, for a given agent (or group of agents) $x$ and world $w, E p i_{x, w}$ is the set of $x$ 's epistemic alternatives in $w$, Conv $_{x, w}$ is the set of worlds where all of $x$ 's conversational goals in $w$ are met, and $C G_{x, w}$ is the set of propositions that $x$ takes for granted in $w$.

$$
\llbracket \operatorname{VERUM}_{x} \rrbracket=\lambda p \lambda w . \forall w^{\prime} \in E p i_{x, w} \forall w^{\prime \prime} \in \operatorname{Conv}_{x, w^{\prime}}\left[p \in C G_{x, w^{\prime \prime}}\right]=: \text { ForSureC }_{x}
$$

Romero \& Han also assume that the use of VERUM (as well as other conversational operators) is only justified in the presence of an epistemic conflict about the prejacent, as per their principle of economy.

This account straightforwardly predicts the distribution of verum accent across contexts. Since contradiction and affirmation contexts involve an epistemic conflict but a neutral context does not, verum accent is correctly expected to occur in the first two contexts and to be ruled out in the last context.

The account does not do so well with deriving the speaker bias profile in verum-marked polar interrogatives, though. The negative direction of the bias is derived from the general assumption that the speaker always seeks evidence for the "pronounced" question alternative, say ForSureCG$G_{x}(p)$. Since the speaker is thus questioning whether $p$ should be added to the common ground, she must consider the negative alternative $\bar{p}$ more likely to be true. This, however, is compatible with the speaker having either a weak or a strong bias towards this negative alternative, although it is unclear what decides on the correct choice to derive the strong bias in polar interrogatives with verum accent. In addition, the optional nature of this bias in unexpected. Since verum accent indicates the presence of VERUM and VERUM necessitates a bias, it remains a mystery why verum accent is a weaker indicator for the presence of bias than is

${ }^{16}$ Other realization possibilities of VERUM are claimed to include accented (low) negation (see Section 3.4), high negation, and epistemic really. 
accented negation. Just like Goodhue (2018), polar interrogatives with verum accent and accented negation are treated on a par, so the respective bias profiles are incorrectly predicted to only differ in polarity.

4.3. Gutzmann et Al. (2020). The final account that we review is that of Gutzmann et al. (2020). Similarly to Romero \& Han (2004), this account views verum accent as the overt realization of a conversational VERUM operator. However, here the signal of VERUM is not part of the at-issue meaning but rather operates on the use-conditional dimension, thus establishing a requirement on how the question under discussion is to be settled. This is stated in (34).

$\llbracket \operatorname{VERUM} \rrbracket_{c}(p)=p$,

provided that the speaker in $c$ wants to prevent that the question under discussion in $c$ is downdated with $\bar{p}$

The use-condition of this version of VERUM implies a rejection of $\bar{p}$ on the part of the speaker and thus creates a sense of an epistemic conflict with the prejacent proposition $p$. This correctly predicts that verum accent is only felicitous in contexts which are conflicted about the prejacent.

The predictions about speaker bias in verum-marked polar interrogatives are less clear. Notice, first, that if VERUM is assumed to apply to the prejacent proposition $p$ directly (and take scope under the $\mathrm{Q}$ operator), we predict a bias of the wrong polarity, i.e. a positive bias. The reason is that if the speaker is trying to prevent that the question under discussion is downdated with $\bar{p}$, she must be doubtful of $\bar{p}$ and willing to believe $p$. In order to deal with this issue, Gutzmann et al. propose that VERUM takes scope over the Q operator and applies to the true answer of the question partition, whichever that might be. Since the speaker is questioning the prejacent proposition as well as pushing against the false answer, she must consider the prejacent proposition to be false, hence the negative bias. As for optionality, the authors suggest that the bias disappears if the speaker is pushing against the prejacent not because they believe the polar alternative but because this alternative has been asserted by another agent (see example (9)). Finally, it remains to be seen how this account would derive the observation that (in contrast to minimally different examples with accented negation) the bias in verum-marked polar interrogatives is strong. Since here verum accenting is distinguished from focus marking, the account could try to pursue a path similar to our own proposal.

5. Conclusion and beyond. This paper argued that verum accent is the overt realization of a VERUM operator, which presupposes an epistemic conflict about the prejacent proposition and which may also generate a negative speaker bias in polar interrogatives. By juxtaposing verum accent to accented negation, we established that such bias is optional and strong. We have thus driven an analytical wedge between verum accenting and polarity focus, in support of Gutzmann et al. (2020) and against Romero \& Han (2004), Goodhue (2018), and others.

We have covered a lot of ground, yet it is also important to emphasize what we have not been able to accomplish. First, we have studied the occurrence of verum accent in declaratives and polar interrogatives. But, as Höhle (1992) points out, verum accent may occur in other sentence types as well, such as $w h$-interrogatives and imperatives. Thus, (35-a) seems to establish a conflict between the question presupposition that someone kicked the dog and a prior utterance suggesting otherwise, while (35-b) constitutes a repeated or emphatic command.

(35) a. Who DID kick the dog? 
b. Do grab a chair and sit down.

In addition, we have limited our attention to root clauses. But verum accent can also occur in subordinate clauses, with apparently the familiar effect of signaling a conflict. (36) demonstrates this for if-clauses and embedded clauses.

(36) a. If Anastasia Is from Russia, she will love the cold winters we get around here.

b. Jack thinks that Anastasia IS from Russia.

Finally, verum accent has uses that may go beyond what we have discussed here. Creswell (2000: 168), for example, introduces the term "dictum focus" for cases in which a salient question has being repeated, as in (37). Also, Horn (1989: 404) discusses the "concessive" use illustrated in (38-a), and Wilder (2013) analyzes similar examples as involving contrastive topic, see (38-b).

(37) a. A: How are we getting there?

b. B: I don't know. How ARE we getting there?

a. We don't have three children, but $\left\{\begin{array}{c}\text { we Do have two } \\ \text { \#we Do have four }\end{array}\right\}$.

b. He might not be a good doctor, but he DOES have a lot of patients $C T$.

We leave the more detailed study of the above-mentioned examples to future work.

\section{References}

Barker, Chris. 2002. The dynamics of vagueness. Linguistics and Philosophy 25. 1-36. https://doi.org/10.1023/A:1014346114955.

Beaver, David I. \& Brady L. Clark. 2008. Sense and sensitivity: How focus determines meaning. London: Wiley-Blackwell.

Beck, Sigrid. 1999. Intervention effects follow from focus interpretation. Natural Language Semantics 14. 1-56. https://doi.org/10.1007/s11050-005-4532-y.

Beltrama, Andrea. 2018. Totally between subjectivity and discourse. Exploring the pragmatic side of intensification. Journal of Semantics 35. 219-261. https://doi.org/10.1093/semant/ffx021.

Büring, Daniel. 2016. Intonation and meaning. Oxford, UK: Oxford University Press.

Creswell, Cassandre. 2000. The discourse function of verum focus in wh-questions. Proceedings of the North East Linguistic Society (NELS) 30(1). 13.

Cruse, D. A. 1986. Lexical semantics. Cambridge: Cambridge University Press.

Goodhue, Daniel. 2018. A minimal theory of verum focus and context dependent bias in questions. Proceedings of the North East Linguistics Society (NELS) 48. 1-10.

Goodhue, Daniel. 2019. High negation questions and epistemic bias. Proceedings of Sinn und Bedeutung 23(1). 469-485. https://semanticsarchive.net/Archive/Tg3ZGI2M/Goodhue.pdf.

Gutzmann, Daniel, Katharina Hartmann \& Lisa Matthewson. 2020. Verum focus is verum, not focus: Cross-linguistic evidence. Glossa: A Journal of General Linguistics 5(1). 51. http://doi.org/10.5334/gjgl.347.

Hamblin, Charles L. 1973. Questions in Montague English. Foundations of Language 10. 4153.

Heim, Irene. 1991. Artikel und Definitheit. In Arnim von Stechow \& Dieter Wunderlich (eds.), Semantik/semantics, 487-535. Berlin/New York: de Gruyter. 
Höhle, Tilman N. 1992. Über Verum-Fokus im Deutschen. In Joachim Jacobs (ed.), Informationsstruktur und grammatik, 112-141. Opladen: Westdeutscher Verlag.

Horn, Laurence R. 1989. A natural history of negation. Chicago: University of Chicago Press. Jackendoff, Ray. 1972. Semantic interpretation in generative grammar. Cambridge, MA: MIT Press.

Kratzer, Angelika. \& Elizabeth Selkirk. 2020. Deconstructing information structure. Glossa: A Journal of General Linguistics 5(1). 113. http://doi.org/10.5334/gjg1.968.

Kratzer, Angelika. 1991. The representation of focus. In Dieter Wunderlich \& Arnim von Stechow (eds.), Semantik/semantics, 825-834. Berlin/New York: Walter de Gruyter.

Laka, Itziar. 1990. Negation in syntax: On the nature of functional categories and projections. Cambridge, MA: MIT dissertation.

Morzycki, Marcin. 2012. Adjectival extremeness: Degree modification and contextually restricted scales. Nat Lang Linguist Theory 30. 567-609. https://doi.org/10.1007/s11049-011-9162-0.

Paradis, Carita. 2001. Adjectives and boundedness. Cognitive Linguistics 12(1). 47-65. https://doi.org/10.1515/cog1.12.1.47.

Partee, Barbara. 2004. Comments on Jason Stanley's 'On the linguistic basis for contextualism'. Philosophical Studies 119(1-2). 147-159.

Reese, Brian \& Nicholas Asher. 2010. Biased questions, intonation and discourse. In Malte Zimmermann \& Caroline Féry (eds.), Information structure: Theoretical, typological, and experimental perspectives, 139-173. Oxford, UK: Oxford University Press.

Repp, Sophie. 2013. Common ground management: Modal particles, illocutionary negation and verum. In Daniel Gutzmann \& Hans-Martin Gärtner (eds.), Beyond expressives: Explorations in use-conditional meaning, 231-274. Leiden: Brill.

Romero, Maribel \& Chung-Hye Han. 2004. On negative yes/no questions. Linguistics and Philosophy 27. 609-658. https://doi.org/10.1023/B:LING.0000033850.15705.94.

Rooth, Mats. 1992. A theory of focus interpretation. Natural Language Semantics 1. 75-116. https://doi.org/10.1007/BF02342617.

Rooth, Mats. 1997. Focus. In Shalom Lappin (ed.), Blackwell handbooks in linguistics: The handbook of contemporary semantic theory. London: Wiley-Blackwell.

Rooth, Mats Edward. 1985. Association with focus. Amherst, MA: University of Massachusetts dissertation.

Sadock, Jerry. 1971. Queclaratives. Proceedings of Chicago Linguistic Society (CLS) 7. 223231.

Samko, Bern. 2016. Syntax \& information structure: The grammar of English inversions. Santa Cruz, CA: University of California dissertation.

Schwarzschild, Roger. 1999. Givenness, AvoidF, and other constraints on the placement of focus. Natural Language Semantics 7. 141-177. https://doi.org/10.1023/A:1008370902407.

Selkirk, Elizabeth. 1995. Sentence prosody: Intonation, stress, and phrasing. In John A. Goldsmith (ed.), The handbook of phonological theory, 550-569. Oxford, UK: Blackwell.

Silk, Alex. 2020. Expectation biases and context management with negative polar questions. J Philos Logic 49. 51-92. https://doi.org/10.1007/s10992-019-09512-0.

Umbach, Carla. 2011. Intensifiers and measure phrases combined with verbs. In Proceedings of the workshop Scalarity in Verb-based Constructions. Universität Düsseldorf: Extended abstract.

Wilder, Chris. 2013. English 'emphatic do'. Lingua 128. 142-171. https://doi.org/10.1016/j.lingua.2012.10.005. 